\title{
EDUCAÇÃO MAKER: ONDE ESTÁ O CURRÍCULO?
}

\author{
Paulo BLIKSTEIN \\ José Armando VALENTE ${ }^{\mathrm{ii}}$ \\ Éliton Meireles de MOURA ${ }^{\text {iii }}$
}

\begin{abstract}
RESUMO
O Movimento Maker tem inspirado instituições educacionais, contribuindo para o crescente interesse pela implantação da educação maker tanto no ensino básico quanto no superior. No entanto, os exemplos dessa implantação mostram que as atividades maker não estão ainda integradas ao currículo. Portanto, o objetivo deste artigo é entender como a educação maker pode ser integrada ao currículo do ensino básico. Para tanto, foram utilizadas a abordagem documental e visitas às instituições que estão implantando a educação maker. Com base nessas experiências, foi possível classificar o material coletado em dois grupos de atividades: as que estão associadas a uma ou duas disciplinas do currículo, e as que não estão relacionadas ao currículo. Com base nesses estudos de caso, discutimos como a implantação da educação maker pode ser feita no ensino básico. $O$ foco dessa educação não deve ser apenas o ensino de conteúdos disciplinares por meio da educação maker, mas também ser capaz de criar condições para que o aluno tome consciência e entenda os conceitos curriculares presentes nos produtos que constroem.
\end{abstract}

PALAVRAS-CHAVE: Movimento maker; Atividade maker; STEM-ampliado; Educação básica; Tecnologias educacionais.

\section{MAKER EDUCATION: WHERE IS THE CURRICULUM?}

\begin{abstract}
The Maker Movement has been inspirational to many educational institutions, contributing to the growing interest in implementing maker education in $\mathrm{K}-12$ and higher education. However, the examples of this implementation show that many maker activities are not yet integrated within the curriculum. The objective of this article is to understand how maker education can be integrated into the K-12 curriculum. Methodologically, this paper uses a qualitative approach, describing case studies in schools implementing maker education. Based on these experiences, it was possible to categorize the material collected into two groups of activities: those developed in schools, but not related to the curriculum; and those related to one or two subjects in the curriculum. Finally, based on these cases, the paper suggests how the implementation of maker education can be carried out in K-12 education. The focus should not only be the teaching of disciplinary content through maker approaches, but be able to create conditions for the student to become aware and understand the curricular topics that are incorporated in the products they build.
\end{abstract}

\footnotetext{
${ }^{i}$ Doutor em Ciência da Aprendizagem pela Northwestern University (2008). Professor associado do Teachers College, Columbia University, e professor afiliado no Departamento de Ciência da Computação e no Data Sciences Institute, Columbia University, EUA. E-mail: paulob@tc.columbia.edu.

ii Doutor pelo Departamento de Engenharia Mecânica e Divisão para o Estudo e Pesquisa em Educação do Massachusetts Institute of Technology MIT. Professor Titular aposentado do Departamento de Multimeios, Mídia e Comunicação do Instituto de Artes e Pesquisador Colaborador do Núcleo de Informática Aplicada à Educação da Unicamp. E-mail: jvalente@ unicamp.br.

iii Doutor pela Faculdade de Educação da Universidade de São Paulo (2019). Pesquisador do Núcleo de Pesquisa em Mídias na Educação (NUPEME) da UFU e Pesquisador do Grupo de Estudos e Pesquisa em Avaliação Educacional (GEPAE) da UFU. E-mail: e.meireles@alumni.usp.br.
} 
KEYWORDS: Maker movement; Maker activity; STEM-rich; K-12 education; Educational technologies.

\title{
EDUCACIÓN MAKER: ¿DÓNDE ESTÁ EL CURRÍCULUM?
}

\begin{abstract}
RESUMEN
El Movimiento maker ha sido observado por las instituciones educativas, contribuyendo al creciente interés en implementar la educación maker en la educación básica y superior. Sin embargo, los ejemplos de esta implementación muestran que las actividades maker aún no están integradas con el currículum. El propósito de este artículo es comprender cómo la educación maker puede integrarse en el currículum. Con este fin, se utilizó el enfoque documental y la visita a las instituciones que están implementando la educación maker. Con base en estas experiencias, fue posible clasificar el material recolectado en dos grupos de actividades: las desarrolladas en las escuelas, pero no relacionadas con el currículum; y los relacionados con una o dos asignaturas del currículum. Finalmente, con base en los estudios de casos descritos y las lecturas realizadas, se describe cómo la implantación de la educación maker puede llevarse a cabo en la educación básica. El enfoque de esta educación no solo debe ser la enseñanza de contenido disciplinario a través del maker, sino también ser capaz de crear condiciones para que el estudiante tome conciencia y comprenda los conceptos curriculares que están presentes en los productos que construyen.
\end{abstract}

PALABRAS CLAVE: Movimiento maker; Actividad maker; STEM-ampliado; Educación básica; Tecnologías educativas.

\section{INTRODUÇÃO}

A educação tecnológica e a científica apresentaram pontos de encontro e desencontro ao longo do último século. Essa história, esquecida no debate educacional atual, pode nos ajudar a iluminar o lugar da educação maker na escola. A educação tecnológica, historicamente, concentrou-se na formação para o trabalho, incluindo a marcenaria e os ofícios industriais (ver, por exemplo, DE VRIES, 2018). Mesmo a educação superior em engenharia, na primeira metade do século XX, era essencialmente prática e incluía uma infinidade de aulas "mão na massa" - o engenheiro "científico", que estuda cálculo e física muito antes de aprender a construir objetos, é uma criação da segunda metade do último século (TRYGGVASON; APELIAN, 2006). As grandes escolas de engenharia do começo do século XX eram templos do engenheiro prático, "mão na massa", mas essas mesmas escolas, nos anos 1970, cultuavam a teoria e a "ciência" da engenharia antes de tudo.

Em níveis primário e secundário, o mesmo ocorreu. Cursos como marcenaria, costura, e "artes manuais" passaram a ser considerados como refúgio dos alunos que não tinham bom desempenho em disciplinas como a matemática, aprofundando a ideia da superioridade do 
trabalho intelectual em relação ao manual. Entretanto, já na década de 1980, vários pesquisadores perceberam que a segregação da tecnologia das aulas "manuais" e a glorificação da ciência e da matemática "do papel e caneta" eram contraditórias com os novos ventos culturais, sociais e econômicos que se delineavam. A Inglaterra, em 1989, criou um currículo de tecnologia para a educação e pesquisadores começaram a perceber que a educação científica e a tecnológica tinham diferenças fundamentais: enquanto a ciência tenta encontrar uma equação que resolve vários problemas (convergente), a engenharia procura descobrir diversas soluções para o mesmo problema (divergente) (ATKIN, 1990).

A inclusão da engenharia e da tecnologia na educação básica, portanto, navegou por décadas em águas turbulentas, tentando impor o modelo tradicional que prioriza o pensamento convergente em um tipo de conteúdo divergente e encontrando poucos caminhos funcionais. Bullock e Sator $(2015$, p. 71) dizem que "Os atuais currículos de ciências fracassam em enquadrar a relação entre ciência e tecnologia como uma relação simbiótica e, portanto, não compreendem que a educação tecnológica cria um espaço para a educação científica e viceversa".

A educação maker, com seu foco na implantação de atividades que combinam ciência e tecnologia (tanto com relação a espaços quanto a temas curriculares), é um novo capítulo nessa história. No entanto, essa educação está baseada em uma série de tecnologias digitais cuja integração na sala de aula, há décadas, encontra dificuldades. O estudo de Iannone, Almeida e Valente (2016) aponta para o fato de que essas tecnologias estão presentes especialmente na parte administrativa e nos laboratórios de informática, elas já fazem parte da vida de muitos professores e alunos. Entretanto, elas ainda não adentraram a sala de aula nem foram incorporadas às práticas curriculares, o que também impacta, agora, a forma de integração da educação maker. No entanto, considerando que tecnologias fazem parte da sociedade contemporânea, que é cada vez mais digital, móvel e conectada, não há como pensá-las senão fazendo parte das atividades pedagógicas e curriculares da sala de aula. O tempo histórico e cultural do início deste século trouxe para a porta das escolas a educação maker.

Este artigo tem como objetivo entender como a educação maker pode ser integrada ao currículo do ensino básico, levando em conta as particularidades dos conteúdos "divergentes" (típicos das atividades maker) com outros tipos de conhecimentos de outras disciplinas e diferentes lógicas de organização curricular. Para tanto, foram utilizados dados coletados em estudos anteriores com o intuito de responder às seguintes questões: Como caracterizar a 
educação maker? Qual a concepção de currículo que pode ser utilizada no desenvolvimento das atividades maker? Como auxiliar o desenvolvimento de conceitos relacionados com o "STEMampliado" (BEVAN, 2017)? Como implantar a educação maker no ensino básico?

Para responder a essas questões são utilizados documentos e exemplos de atividades e de espaços maker visitados pelos autores, bem como de experiências vividas na criação de espaços maker e realização de oficinas para formação de professores. $\mathrm{O}$ artigo está dividido em cinco seções, e a primeira delas aborda sobre a conexão entre o currículo e as atividades maker. Em seguida, vêm as seções sobre integração das atividades maker no currículo, apresentando e discutindo exemplos práticos; sobre a implantação da educação maker no ensino básico; e finalmente uma conclusão.

\section{OS PILARES DA EDUCAÇÃO MAKER E O CURRÍCULO}

Nesta seção são apresentados os tópicos sobre origens da educação maker, visão sobre o currículo e a relação entre educação maker e o STEM-ampliado.

\subsection{Origens da educação maker}

O Movimento Maker, fundamentando-se na cultura do "faça você mesmo", do inglês Do-it-Yourself (DIY), é apenas um dos pilares da educação maker. Esse movimento traz por essência a ideia de que pessoas comuns podem construir, consertar, modificar e fabricar os mais diversos tipos de objetos e projetos. O coletivo constituído pelos Makers reúne adeptos em espaços físicos com objetos tradicionais e máquinas de fabricação digital, chamados espaços maker, makerspaces, hackerspace, FabLabs, FabLearn labs, e outras denominações.

Os FabLabs são um importante pilar do movimento maker. No começo da década de 2000, Neil Gershenfeld e colaboradores no Massachusetts Institute of Technology (MIT) Media $L a b$ criaram um espaço de fabricação digital de relativo baixo custo e passaram a levar o modelo para fora do campus. Nesses espaços, por meio do acesso a ferramentas de fabricação digital, alunos estudavam as "fronteiras entre ciência da computação e ciência física" (GERSHENFELD, 2012, p. 46). Desde então, a rede de FabLabs se expandiu para comunidades, museus, bibliotecas, feiras de ciências e, por fim, alcançou as instituições de ensino. 
A educação maker tem outros pilares históricos - a Maker Faire e a MAKE Magazine, criadas nos EUA em 2006, popularizando as práticas DIY; o projeto FabLearn, que semeou comunidades de educadores maker e construiu os primeiros espaços em escolas em dezenas de países desde 2010 (MARTINEZ; STAGER, 2013). Mas a ideia do "faça você mesmo" na educação, claro, não é nova: foi proposta por educadores como Dewey (1916), Freinet (1998), Montessori (1965) e Freire (2008), que discutem abordagens pedagógicas baseadas no "mão na massa", usando as tecnologias da época, como cartas, madeira etc. A pedagogia fundamentada no "mão na massa", utilizando-se as tecnologias digitais, foi proposta por Papert e colaboradores (que cunharam o termo "construcionismo"), que se pauta pela ideia de que o conhecimento se realiza quando o aprendiz está engajado na produção de um objeto de seu interesse (PAPERT, 1986). As tecnologias digitais, especialmente os computadores, adquirem um papel de destaque porque "eles fornecem uma gama especialmente ampla de excelentes contextos para a aprendizagem construcionista" (PAPERT, 1991, p. 8). A tradição intelectual do Construcionismo é, portanto, outro pilar importante já que "preparou o terreno" teórico para que educadores maker construíssem uma compreensão mais profunda de suas próprias práticas.

Mas o fato da aprendizagem maker ter muitos pilares históricos fez com que ela nunca fosse propriamente definida. Isso criou uma enorme gama de possibilidades, desde o uso de objetos simples, como palito de sorvete, papelão, cola etc., até o uso de ferramentas de fabricação, como cortadores a laser, fresadoras digitais e impressoras 3D. Esse grande número de possibilidades e recursos oferecido pelo movimento maker tem proporcionado diferentes caminhos para que a escola incorpore essas ideias. Diversos pesquisadores têm observado que a produção de objetos ou o desenvolvimento de uma aprendizagem baseada em metodologias construcionistas, como as oferecidas pelas atividades maker, podem propiciar as condições para que os aprendizes sejam criativos e críticos, bem como capazes de resolver problemas e trabalhar em grupo (MARTINEZ; STAGER, 2013; HALVERSON; SHERIDAN, 2014; KURTI; KURTI; FLEMMING, 2014; BLIKSTEIN; WORSLEY, 2016).

Entretanto, ainda resta o desafio de vincular as atividades maker ao currículo, procurando não esquecer a enorme riqueza que faz parte do processo de construção de objetos, mas sem perder de vista a necessidade de gerar aprendizado, como afirmam Valente e Blikstein (2019). Isso requer não se perder no encantamento com as infinitas possibilidades e recursos disponíveis nessas atividades esquecendo o objetivo educacional. 
Valente e Blikstein (2019), ainda, sustentam que existe uma grande diversidade de objetivos dentro da educação maker, apesar da aparência de unicidade. Em seu estudo, eles notam que mesmo em escolas muito próximas havia grande diversidade de objetivos. Em uma delas, o objetivo não era necessariamente trabalhar conteúdos curriculares, mas sim aumentar a autoestima dos alunos. $\mathrm{O}$ contexto social e cultural em que esses alunos viviam era bastante desfavorecido, o que lhes rendia baixa estima quanto à capacidade de realizar algo com sucesso e de aprender. Assim, a preocupação do professor era a de criar um ambiente no qual os alunos fossem capazes de fazer algo com sucesso e compartilhar o produto com os colegas e familiares. Em uma outra escola no mesmo distrito, o objetivo da atividade era realizar algo de grande valor estético, com um produto bem-acabado. Portanto, em algumas situações, deve-se levar em consideração as circunstâncias e necessidades dos alunos e da comunidade. Dessa forma, a educação maker nem sempre está alinhada a objetivos ligados ao currículo da escola, mas quando está, deve haver clareza de que o fazer não implica em aprender: são necessários elementos explícitos de desenho educacional para conectar educação maker e o currículo.

\subsection{Visão sobre currículo}

No Brasil, os Parâmetros Curriculares Nacionais - PCN (BRASIL, 1997), as Diretrizes Curriculares Nacionais para a Educação Básica - DCNEB (BRASIL, 2013) e, mais recentemente, a Base Nacional Comum Curricular - BNCC (BRASIL, [s.d.]) foram criados com o objetivo de orientar as escolas de Ensino Básico sobre os conteúdos comuns. Uma das competências da BNCC, a cultura digital, é proporcionar oportunidades para o trabalho com tecnologia no sentido de estimular a curiosidade dos alunos, bem como o "pensamento criativo, lógico e crítico, por meio da construção e do fortalecimento da capacidade de fazer perguntas e de avaliar respostas, de argumentar, de interagir com diversas produções culturais" (BRASIL, [s.d.], p. 58). Assim, o processo pedagógico deve contemplar o desenvolvimento de distintas linguagens, metodologias e múltiplas direções nas interações entre aprendizes, professores, materiais didáticos e uso de tecnologias digitais, que devem fazer parte do currículo e do plano pedagógico da escola.

A possibilidade de ressignificar e de adaptar o currículo é compartilhada por diferentes autores, por exemplo, Gimeno Sacristán (1998; 1999; 2000), que entende o currículo como uma práxis social que engloba conteúdos, métodos, procedimentos, instrumentos culturais, 
experiências prévias e atividades. Para esse autor, a escola convive com um currículo oficial, prescrito e com um currículo real, que se estabelece no contexto formativo e é experienciado na prática concreta, na relação entre professor e aluno e entre alunos. Contudo, tanto o currículo prescrito quanto o real, segundo Freire (2008) e Pacheco (2000), devem envolver o social, o político e o cultural. Pacheco (2016) enfatiza que a centralidade do currículo é o conhecimento, compreendido como uma produção histórica.

Uma vez que o currículo real é um espaço fundamentalmente deliberativo, conforme Pacheco e Paraskeva (1999), ele é parte de um projeto que envolve intenções e práticas, o que implica um continuum de tomadas de decisão e, portanto, um processo inacabado que integra opções, dimensões valorativas, atitudinais e técnicas. As dimensões valorativas e atitudinais contribuem para que o currículo vivenciado em sala de aula não seja neutro.

É importante assumir que o currículo em execução na educação maker não é neutro. Todos são "atores curriculantes”, como propõe Macedo (2013), que entende o currículo como um conceito processual, e os cenários curriculares funcionam como "agoras curriculares", ou seja: “espaços-tempos nos quais todo e qualquer ator social envolvido nas 'coisas' do currículo seja ouvido como importante para a democratização de um artefato inventado socialmente" (MACEDO, 2013, p. 429), e que, como mencionado pelo autor, acaba reproduzindo situações autocráticas e provocando exclusões.

Nesse sentido, o conceito de atos de currículo é bastante relevante para compreender os contextos de aprendizagem criados nos espaços maker, pois o currículo não deve ser algo construído por autoridades educacionais e a ser aplicado por educadores. As atividades a serem desenvolvidas nos espaços maker devem ser pensadas como atos de currículo de modo que a aprendizagem, a negociação de significados e a atribuição de sentido tenham origem na interação social com as pessoas, com os materiais e com as tecnologias presentes nesses espaços. O currículo não é definido a priori e imposto, mas é baseado na intencionalidade pedagógica do professor, reconstruída pelas ações dos alunos e do professor.

Para que a educação maker possa dar suporte aos atos de currículo e à interdisciplinaridade, é importante que a integração das atividades maker ao currículo das disciplinas seja realizada de forma fundamentada e não como modismo. Primeiro, a tecnologia deve ter uma função de auxiliar a realização de algo que não pode ser feito adotando métodos convencionais. Segundo, é necessário nivelar a tecnologia à proposta educativa, ou seja, não é 
sensato utilizar vários equipamentos tecnológicos para abordar um conteúdo que não os demanda.

A Figura 1 ilustra o balanço que deve guiar a criação de atividades educacionais maker: de um lado, o currículo, que para ser colocado em prática envolve a formação do professor, o desenvolvimento científico e o conhecimento a ser trabalhado; de outro, o trabalho maker, envolvendo criação, desenvolvimento tecnológico e o mundo real. A metáfora da balança indica que esses dois componentes devem estar em equilíbrio - não pender para o lado do currículo, nem para as práticas maker.

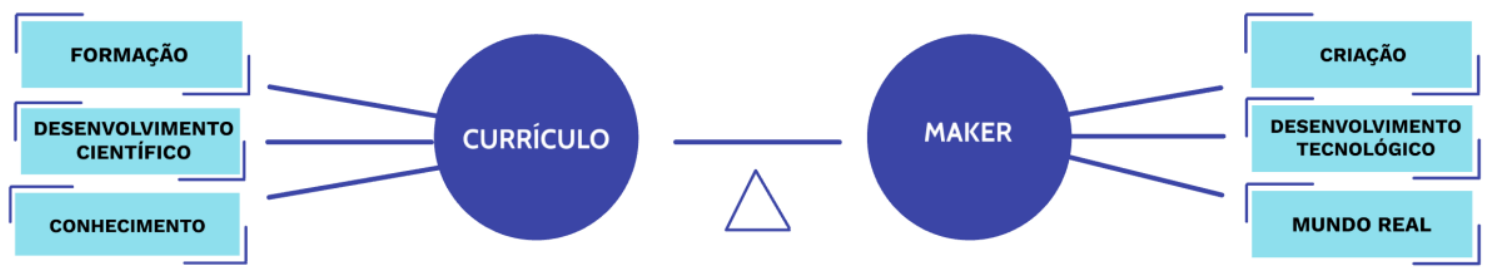

Figura 1 - Balanço entre Currículo e Maker. Fonte: autores

Equilibrar essa balança significa considerar a formação e a criatividade, desenvolvendo ao mesmo tempo aspectos científicos e tecnológicos. Os projetos que envolvem a fabricação digital e tecnologias avançadas estão quase que exclusivamente relacionados à prática das disciplinas STEM, embora autores como Bevan (2017) têm considerado atividades em outras disciplinas (o STEM-ampliado).

\subsection{A relação entre educação maker e o STEM-ampliado}

Um dos argumentos usados para justificar a implantação da educação maker no ensino básico americano (K-12) é a possibilidade de dar suporte à integração curricular das disciplinas de ciência, tecnologia, engenharia e matemática, o que ficou conhecido como STEM. Embora a integração das disciplinas STEM seja desejável, ela ainda não acontece de maneira satisfatória, como aponta o relatório do National Research Council (2014).

A educação maker tem sido considerada uma solução para essa integração (BLIKSTEIN, 2013; HALVERSON; SHERIDAN, 2014; RILEY, 2015; ROSE，2014; SHERIDAN et al., 2014). Além dessa integração à educação maker, há condições para que os alunos possam ser mais protagonistas, desenvolver projetos usando objetos tradicionais e 
tecnológicos e poder trabalhar projetos autênticos em espaços flexíveis e colaborativos (VUORIKARI; FERRARI; PUNIE, 2019). Além das disciplinas do STEM, a educação maker tem possibilitado o trabalho com artes (PEPPLER, 2016) e design (MARTIN; DIXON, 2016), ampliando o escopo de disciplinas, o que Bevan (2017) tem denominado STEM-ampliado ou STEM-rich.

Outro aspecto importante é que as atividades realizadas nos espaços maker podem contribuir para o desenvolvimento pessoal e social dos aprendizes. Clapp e colegas (2017) identificaram que os alunos assumem um papel mais proativo com relação aos problemas do mundo e à construção de caráter - eles podem correr riscos, aprender a lidar com falhas e alcançar sucesso e desenvolver uma mentalidade que inclui criatividade, curiosidade, persistência, responsabilidade social e trabalho em equipe.

Finalmente, existe uma grande preocupação da educação maker com a equidade de participação de todos os alunos. Buechley, em 2013, apontou que $89 \%$ dos autores e $81 \%$ dos leitores da Make Magazine eram do sexo masculino (BUECHLEY, 2013). Especialmente nos EUA, essas questões têm sido o foco de pesquisa de diversos grupos e autores de modo que a educação maker não se torne elitista, atendendo a uma classe privilegiada de alunos (BLIKSTEIN; WORSLEY, 2016; CALABRESE BARTON; TAN, 2018). O objetivo é poder valorizar a cultura, as experiências e os valores que os alunos trazem para os processos de ensino e de aprendizagem.

Na próxima seção são apresentados e discutidos exemplos de como temas curriculares podem ser identificados em atividades que os alunos desenvolvem na educação maker.

\section{INTEGRAÇÃO ENTRE ATIVIDADES MAKER E O CURRÍCULO}

Nesta seção, são discutidos exemplos de atividades educacionais realizadas em escolas, sendo um caso não relacionado ao currículo e o outro referente ao STEM-ampliado.

\subsection{Atividades maker não relacionadas ao currículo}

A atividade maker aqui discutida foi relatada por Moura (2019) em visita a uma instituição escolar pública norte-americana no subúrbio da cidade de Palo Alto, na Califórnia, descrita como estudo de caso: Os barcos no aquário.

Em uma de suas atividades educacionais, o técnico responsável pelo espaço maker promoveu uma competição com uma turma de 5 a 6 anos de idade. Ao entrarem no espaço 
maker escolar, os alunos depararam com um aquário cheio d'água, posicionado no meio da sala. O técnico, já com a turma sentada à sua frente, começou explicar a dinâmica da atividade do dia. Cada aluno construiria um barco e, para isso, teriam à disposição alguns materiais facilmente manuseáveis, presentes no espaço maker, tais como tipos diferentes de papel, plástico, barbantes, colas e algumas sucatas. Por conta da faixa etária e por ser uma atividade planejada para uma única aula, outras opções não foram cogitadas para essa atividade, como o uso das impressoras 3D. O técnico ainda explicou que, depois de ter construído seu barco, cada aluno iria até o aquário e testaria sua embarcação. O barco deveria suportar um grande número de bolas de gude, sem afundar. Seria considerado o "vencedor" da tarefa aquele estudante que construísse o barco que suportasse a maior quantidade de bolas.

As crianças então partiram para a atividade. Construíam seu barco, vinham até o aquário para testá-lo, onde o depositavam, e colocavam elas próprias as bolas de gude, contando-as até que o barco afundasse. Instruções para mudar o material ou não inserir muitas bolas de uma só vez eram constantes por parte do técnico. Ele também questionava as crianças o porquê de alguns de seus projetos não terem sucesso. Ao final da atividade, uma das crianças, uma menina, foi declarada campeã com 12 bolas sustentadas em sua embarcação de papel alumínio, fita e pedaços de isopor colados nas bordas. Após o término da atividade, o técnico solicitou que as crianças fossem para o pátio e fizessem uma roda para discutir a atividade. Nesse momento, o técnico conduziu um debate sobre a importância do planejamento antes da execução do projeto. Não demorou muito e um sinal sonoro indicou o final da aula, fazendo com que os alunos corressem para a sala de aula regular. A Figura 2 ilustra os diferentes momentos da atividade. À esquerda, as crianças na construção do barco, ao centro as tentativas de flutuação de alguns dos barcos, e à direita, a roda de conversa.
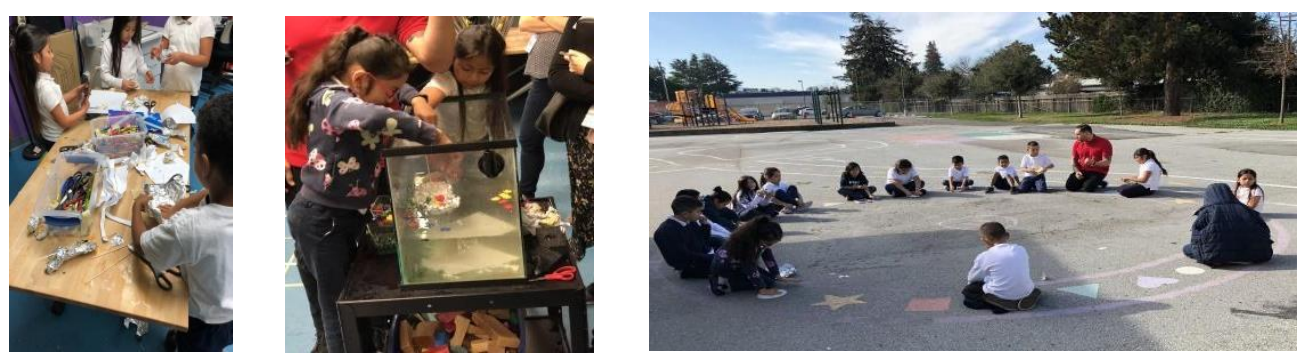

Figura 2 - Atividades Maker "O Barco e o Aquário". Fonte: Moura (2019).

A atividade foi bem aceita e desenvolvida pelos alunos com muito envolvimento. Ela foi apresentada pelo técnico como uma ação divertida, o que foi comprovado pelas atitudes dos 
estudantes. Embora não tenha sido explicitado, essa atividade possibilitou trabalhar diversas competências, como a autonomia diante das escolhas dos materiais, o compromisso para atingir o objetivo proposto com entusiasmo e esforço, além de persistência, resiliência e versatilidade. Posto isso, também é importante verificar duas ausências bastante significativas, a do professor e, consequentemente, a dos conteúdos curriculares.

O técnico de um espaço educacional maker, por via de regra, tem sob sua responsabilidade a manutenção e o gerenciamento do ambiente. É do professor a responsabilidade de estar à frente da turma escolar num espaço educacional. Assim, justificada ou não, a ausência do próprio docente acaba por forçar a figura do técnico a assumir o papel de professor, tendo de elaborar e desenvolver atividades escolares com os estudantes. Assumir tal papel docente é inadequado, porquanto esse profissional geralmente não tem formação pedagógica e, por isso, não é, e de fato não deveria ser, responsável por ministrar conteúdos escolares. Em decorrência dessa situação, o conteúdo curricular acaba sendo abandonado. Com efeito, majoritariamente, a própria pesquisa de Moura (2019) aponta que as atividades maker não têm sido orquestradas para trabalhar conteúdos curriculares, mas sim competências cognitivas, motoras e socioemocionais. Em contrapartida, em alguns espaços maker é possível notar o desenvolvimento de atividades maker relacionadas ao currículo, inclusive às disciplinas do STEM-ampliado.

\subsection{Atividades maker relacionadas ao STEM-ampliado}

Blikstein (2013) apresenta em "Digital Fabrication and Making in Education” um projeto desenvolvido por uma professora de história que queria dar suas aulas no laboratório maker. Mesmo não sendo familiarizada com prototipagem digital, a professora, amparada pelo professor do espaço maker, buscou compreender as possibilidades dos recursos ali presentes e, então, propôs à sua turma que aprendessem sobre grandes personagens femininas da história dos EUA (como Rosa Parks), construindo monumentos históricos para elas, usando impressão $3 \mathrm{D}$ e a cortadora a laser. O projeto contou com a participação do professor de matemática, que criou a base dos monumentos com quadrados espaçados em 2,5 cm (uma polegada) e incluiu na tarefa a obrigatoriedade de todos os objetos serem construídos em escala - estabelecendo então uma conexão autêntica e rica com a sua disciplina. A Figura 3 expõe três dos monumentos. 

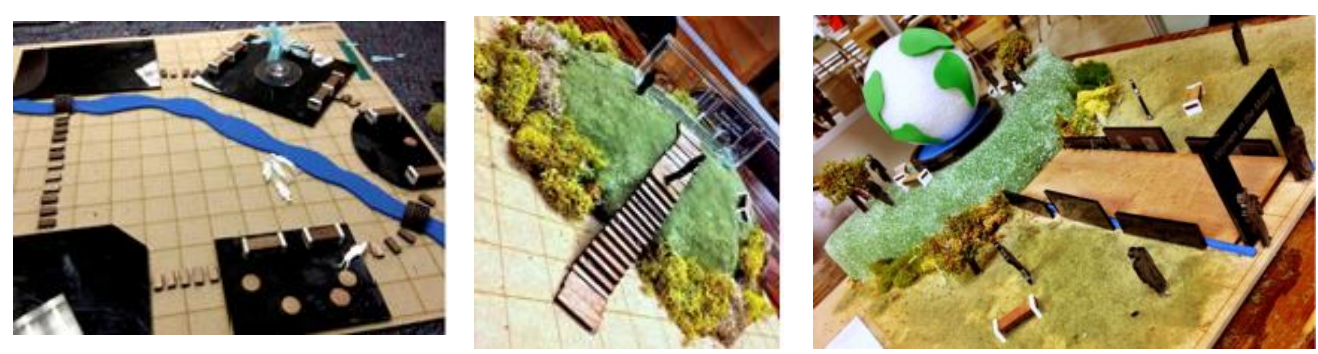

Figura 3 - Três exemplos de projetos dos "Monumentos Históricos", mostrando a "grade" de $2.5 \mathrm{~cm}^{2}$ sugerida pelo professor de matemática para orientar a criação dos objetos em escala.

Fonte: Blikstein (2013).

Esse projeto pode ser caracterizado como uma atividade educacional maker que não está totalmente relacionado com as ciências "duras," uma vez que inclui, além da matemática, conteúdos disciplinares de História. O primeiro passo para criar uma atividade curricular maker é pensar o objetivo de aprendizagem - que deve vir antes da escolha de tecnologia.

Em um outro projeto em uma escola brasileira, o foco foi o currículo de História Geral, focando nos povos da Antiguidade. O objetivo era avaliar as variadas técnicas e materiais usados por diferentes civilizações, relacionar essas informações com suas características, organização social e contexto histórico e, com base nessas informações, construir objetos semelhantes por meio das ferramentas de fabricação do espaço maker.

No estudo das grandes civilizações da Antiguidade, o docente da disciplina de História propôs que a turma fosse dividida em grupos e cada qual escolhesse um dos grandes povos da história humana. Essa escolha poderia ser por região, por exemplo, os povos que habitaram a região da Mesopotâmia, como os Acádios, Babilônios, Assírios e Caldeus; ou por época, optando por povos em regiões distintas, mas em uma mesma época (chineses, gregos, romanos, egípcios etc.). Feito isso, a primeira, de quatro fases pensadas para essa atividade, consistiu em estudar a cultura do povo escolhido, com foco principalmente nos artefatos/objetos utilizados por eles, seus materiais, tecnologias e formas de escrita logográfica. A fase seguinte consistiu na criação e produção de artefatos históricos como moedas, utensílios, placas com símbolos e escrituras semelhantes ao que foi pertencente à civilização escolhida pelo grupo. Para essa tarefa foi recomendado o uso de várias tecnologias maker como impressora 3D, cortadora a laser, moldagem de polímeros, material de marcenaria, argila, entre outras. Na terceira fase, a proposta foi criar escavações para que os grupos trocassem de sítios arqueológicos e descobrissem de que civilização são os objetos produzidos. Finalmente, na quarta fase, articulados pelo professor, os estudantes discutiam diversos aspectos da conexão entre 
tecnologias, materiais e contexto histórico, por exemplo, entendendo como a descoberta de um novo material ou técnica de fabricação muda a economia e o contexto social de uma civilização. Essa é uma atividade que, assim construída, pode ser de curta duração, por exemplo, de uma a duas semanas, ou longa, levando meses, dependendo da opção do professor e seus objetivos de aprendizagem.

Nesses três casos, um fator importante a ser notado é o papel do professor em relacionar ou não a atividade com o currículo. No caso da atividade Os barcos no aquário, considerando a faixa etária dos estudantes, ela poderia ter sido usada para explorar conceitos do currículo de matemática, como as formas geométricas dos barcos construídos, procurando identificar quais são mais indicadas para manter os barcos flutuando. Poderia ainda discutir com as crianças as referências de barcos reais e históricos ou conceitos de Ciências, como o empuxo, e práticas científicas, como a experimentação sistemática. A ausência de um currículo trabalhado nessa atividade realça a falta da participação de um professor que sabe como explorar os produtos que os alunos desenvolvem para entender os conceitos disciplinares abordados.

\section{IMPLANTAÇÃO DA EDUCAÇÃO MAKER}

A implantação da educação maker deve ser embasada em quatro pilares: a criação do espaço maker; a formação de professores; os projetos a serem desenvolvidos; e o protagonismo dos alunos. O espaço maker é o local em que os alunos desenvolvem as atividades. O ideal seria que a escola fosse, na verdade, um grande espaço maker, no qual alunos de diferentes idades e professores de disciplinas distintas pudessem interagir e desenvolver projetos, explorando de forma integrada variados conceitos, habilidades e atitudes, como já acontece com algumas escolas maker - por exemplo, a escola Acera - The Massachusetts School for Science, Creativity and Leadership (ACERA, 2020).

A criação dos espaços maker nas escolas assume vários formatos. Em algumas escolas, temos salas especiais que dispõem de materiais educacionais tradicionais (cola, papelão, madeira), sucatas e tecnologias digitais, como impressora 3D, cortadora a laser e fresadora digital. Em outras escolas, temos a combinação de um espaço com essas mesmas características mas com materiais que abarcam todas as disciplinas. Finalmente, há instituições que criam um "canto maker" na própria sala de aula. Nesse último caso, as construções básicas podem ser iniciadas na sala de aula e complementadas com o uso das ferramentas digitais de fabricação. Assim, o espaço maker pode ser entendido como a combinação de diversos locais que podem 
existir na escola, como sala de arte, laboratório de ciências, oficina de reparação (LECORCHICK; SPIRES; GALLO, 2019).

No entanto, é importante enfatizar a presença das tecnologias digitais como parte do espaço maker, conforme afirmam Valente e Blikstein (2019). Elas maximizam possibilidades: uma coisa é pintar com o dedo e com apenas uma cor de tinta, outra é ter à disposição uma infinidade de cores e vários tipos de pincéis. A qualidade das ferramentas e dos materiais expandem as possibilidades de construção. Além disso, as tecnologias devem ser mais do que auxílio na produção de um determinado produto. Podemos fazer um vaso a partir de uma de argila, mas programar um robô para realizar a mesma coisa é uma tarefa radicalmente diferente (apesar do mesmo produto final). No caso do robô e das ferramentas digitais de fabricação, para que elas funcionem, elas devem ser programadas, cujo programa constitui a representação do conhecimento do aluno no tocante a conceitos, como escala, distância, geometria e programação. Essa representação pode ser estudada e analisada no âmbito dos conceitos e estratégias utilizados e pode ser melhorada ou depurada, ajudando o aluno a atingir um novo nível de conhecimento científico por meio da espiral crescente de aprendizagem (VALENTE, 2005).

O professor, para ser capaz de auxiliar o processo de construção de conhecimento a partir das atividades maker que o aluno realiza, deve ser preparado não só em matéria de conteúdo da disciplina que ministra e do uso das tecnologias disponíveis no espaço maker, mas sobre como integrar as atividades dos alunos com as disciplinas do currículo e como desafiar os alunos para que possam continuar a espiral crescente de aprendizagem.

Assim, uma atitude positiva do professor com relação à educação maker é ser protagonista. Apesar do discurso contrário, a escola pouco mostra, na prática, preocupação em conectar seus currículos a situações reais da vida ou aos interesses dos alunos. A possibilidade de pensar as atividades dos alunos como "agora curriculares", como proposto por Macedo (2013), cria as condições para os professores, a partir de sua intencionalidade pedagógica, incorporarem os interesses e necessidades dos alunos.

O professor, como principal agente da instituição escolar e da sala de aula, precisa ter consciência de que a prática docente, em geral, é pouco compromissada com a criação, uma vez que responde ao livro didático, ao currículo prescrito ou a qualquer coisa que não é aquilo que está ocorrendo naquele momento na sala de aula. Não que o docente deva abandonar tais 
referências ou o seu planejamento, mas as propostas guiadas e excessivamente "engessadas" de educação maker ainda são "muletas pedagógicas".

A aprendizagem pelo fazer retoma a condição natural da experimentação, da curiosidade e da criatividade, permitindo àqueles que a praticam envolver em atividades em que possam criar coisas intuitivamente, indo além de apenas interagir com a tecnologia. Entretanto, essa curiosidade deve ser epistemológica, uma "inquietação indagadora", como proposto por Freire (2000, p. 35). Por outro lado, apenas fazer algo significativo e criativo não justifica a atuação do professor, é necessário também se preocupar com a rigorosidade metódica (WEFFORT, 1996) e, consequentemente, com o conteúdo curricular envolvido nas atividades maker.

No que diz respeito aos projetos desenvolvidos pelos alunos, como foi mencionado em outras seções deste artigo, eles devem ser integrados com o currículo das disciplinas e com o plano pedagógico da escola. Kim e colegas (2019), concordando com Freire (1968), observaram que os alunos têm mais chance de se engajar em suas atividades e de desenvolver maior interesse em aprender, se os projetos que realizam são relacionados com a realidade em que vivem. Esses autores mencionam que os projetos podem tratar de temas sobre a comunidade escolar ou acerca do contex to onde os alunos vivem, por exemplo, onde os alunos podem aplicar as habilidades e os conceitos aprendidos no espaço maker na manutenção de objetos escolares ou de objetos que melhorem a escola ou onde vivem.

No entanto, Kim e colegas (2019, p. 10) encontraram nos espaços maker que estudaram "lições pré-construídas, instruções empacotadas fornecidas como kits de atividade ou currículos desenvolvidos por organizações governamentais". Os técnicos ou professores desses espaços maker que foram entrevistados preferiam essas lições em virtude de sua conexão com a comunidade global do FabLab e os recursos online disponíveis. Alguns alunos também escolhiam ter projetos e processos criativos detalhados, uma vez que essas facilidades "reduziam a ansiedade e proporcionavam oportunidades guiadas por meio de novas experiências no espaço maker" (KIM et al., 2019, p. 10).

Outros espaços maker estudados por esses autores, que tinham uma concepção mais aberta, enfatizando projetos mais pessoais, mostraram que o "senso de empoderamento e capacidade de atuação que os alunos desenvolveram através da natureza flexível do currículo aberto lhes permitiu aplicar as habilidades adquiridas fora do ambiente maker (KIM et al., 2019, p. 10). 
Portanto, a atuação do aluno, ou seja, o quarto pilar da educação maker, está diretamente relacionada com o tipo de abordagem pedagógica e de currículo desenvolvido. Um currículo pré-formatado permite que o aluno tenha acesso ao material proporcionado pela comunidade maker, podendo obter pistas de como prosseguir em suas produções de maneira mais "eficiente". Parece que aqui o foco é conseguir o produto com menos dificuldade e em menor tempo. Por outro lado, alunos em uma abordagem mais aberta do ponto de vista curricular podem desenvolver seu interesse pessoal, criar projetos de seu interesse, ser mais criativos e ter um maior engajamento em suas atividades.

A implantação da educação maker pode tomar dois caminhos distintos: um mais focado na produção, outro em ideias, conceitos e atitudes dos alunos. Nesse sentido, é fundamental pensar que tipo de educação está sendo esperada com essa implantação para que não se torne uma experiência frustrante, como a tentativa de colocar "um prego quadrado" em um "buraco redondo", ou seja, uma abordagem pedagógica inovadora em um sistema educacional arcaico.

Como afirma Gilbert (2017), a educação maker pautada por um currículo flexível, no modelo dos "agora curriculares", com disciplinas integradas, professores trabalhando juntos e baseada em projetos tem grande chance de tornar o ensino tradicional instrucionista ainda mais anacrônico. A questão é se trilharemos o caminho de uma educação maker realmente transformadora, ou se ela se transformará em mais um "faz de conta" pedagógico, sem concretizar mudanças.

\section{CONSIDERAÇÕES FINAIS}

A preocupação neste artigo foi diferenciar atividades de educação maker feitas em contextos escolares em duas modalidades. Em uma, as atividades são explicitamente relacionadas ao currículo e há conexões intencionais com as disciplinas escolares. Na outra modalidade, as atividades não tem nenhuma conexão clara com o currículo. Nessas duas situações, e principalmente na segunda, embora os alunos estejam "construindo" e engajados, não há garantia de que isso se traduz em aprendizado de conteúdos disciplinares. Este não acontece de maneira satisfatória sem a articulação clara do professor na criação de objetivos de aprendizagem originais e na integração das tecnologias maker de forma relevante e apropriada. Essa articulação passa pelo entendimento de como as tecnologias maker podem, de fato, 
transformar a atividade e enriquecer os objetivos de aprendizagem, em vez de simplesmente se tornarem "penduricalhos" em currículos ainda convencionais.

Modismos e falsas revoluções infestam o mundo educacional nesse começo de século XXI. Teorias (como o construcionismo) são renomeadas, ideias essenciais são sistematicamente trivializadas (como a pedagogia de Paulo Freire) e o trabalho de educadores inovadores (como a educação maker) corre risco de ser deglutido pelas forças do tradicionalismo. Acreditamos que a integração das tecnologias e ideias da educação maker ao currículo seja um passo crítico para solidificar a agenda de transformação de Papert, Dewey, Freire e outros. Ao manter a educação maker fora da escola e do currículo, não atacamos as possibilidades de oferecimento democrático dessas oportunidades a todos os alunos. Mas não é só: também mantemos a educação maker como uma atividade "extra", opcional e apenas "divertida", perdendo seu papel de agente transformador na espinha dorsal da escola - o currículo.

Entretanto, quando trazemos a educação maker para o currículo como mero adorno a uma sequência didática fixa e inflexível, que nega a alunos o protagonismo e ao professor seu papel de criador curricular, guia e sistematizador, também prestamos um desserviço à transformação da escola porque esses caros adornos tecnológicos não vão trazer mais aprendizagem, e serão, possivelmente, rapidamente descartados.

Resta-nos, portanto, tentar fazer da educação maker não mais um modismo ou palavra de ordem, mas uma força de real reorganização curricular na escola. Sem intencionalidade pedagógica, sem teorias educacionais que atuem como guias para a criação de atividades, sem uma preocupação com a democratização de oportunidades, sem um entendimento do papel mediador e amplificador das tecnologias, a educação maker corre o risco de se transformar em um marca tão genérica quanto vazia, um elemento de marketing e não de emancipação, um domínio de "consultores" e não de educadores. E assim, novamente, estaremos negando a nossos alunos mais uma oportunidade de educação libertadora.

\section{REFERÊNCIAS}

ACERA. The Massachusetts School for Science, Creativity and Leadership. 2020. Disponível em: www.aceraschool.org. Acesso em: 9 abr. 2020.

ATKIN, J. Myron. Teach Science for Science's sake; for global competitiveness, try technology. Education Week (Commentary), v. 10, n. 4, p. 32, 1990. Disponível em: 
https://www.edweek.org/ew/articles/1990/09/26/teach-science-for-sciences-sake-forglobal.html. Acesso em: 12 abr. 2020.

BEVAN, Bronwyn. The promise and the promises of making in science education. Studies in Science Education. London, v. 53, n. 1, p. 75-103, 2017. Disponível em: doi:10.1080/03057267.2016.1275380. Acesso em: 3 abr. 2020.

BLIKSTEIN, Paulo. Digital fabrication and "making" in education: the democratization of invention. In: WALTER-HERRMANN, Julia; BÜCHING, Corinne (Eds.). FabLabs: of machines, makers and inventors. Bielefeld: Transcript Publishers, 2013. p. 203-221.

BLIKSTEIN, Paulo; WORSLEY, Marcelo. Children are not hackers: building a culture of powerful ideas, deep learning, and equity in the Maker Movement. In: PEPPLER, Kylie; HALVERSON, Erica R.; KAFAI, Yasmin B. (Eds.). Makeology: makerspaces as learning environments. New York: Routledge, v. 1, 2016, p. 64-79.

BRASIL. Ministério da Educação. Base Nacional Comum Curricular: educação é a base. [s.d.]. Disponível em:

http://basenacionalcomum.mec.gov.br/images/BNCC_EI_EF_110518_versaofinal_site.pdf. Acesso em: 16 abr. 2020.

BRASIL. Secretaria de Educação Fundamental. Parâmetros Curriculares Nacionais: introdução aos parâmetros curriculares nacionais. Secretaria de Educação Fundamental. Brasília: MEC/SEF, 1997. 126p. Disponível em:

http://portal.mec.gov.br/seb/arquivos/pdf/livro01.pdf. Acesso em: 2 abr. 2020.

BRASIL. Ministério da Educação; Secretaria de Educação Básica; Secretaria de Educação Continuada, Alfabetização, Diversidade e Inclusão; Secretaria de Educação Profissional e Tecnológica. Conselho Nacional de Educação; Câmara de Educação Básica. Diretrizes Curriculares Nacionais da Educação Básica. Brasília: MEC; SEB; DICEI, 2013. Disponível em: http://portal.mec.gov.br/index.php?option=com_docman\&view=download\&alias=13448diretrizes-curiculares-nacionais-2013-pdf\&Itemid=30192. Acesso em: 16 abr. 2020.

BUECHLEY, Leah. Palestra de abertura. FabLearn 2013. Stanford University, USA, October 2013. Disponível em: http://leahbuechley.com/?p=60. Acesso em: 12 abr. 2020.

BULLOCK, Shawn M.; SATOR, Andrea J. Maker pedagogy and science teacher education. Journal of the Canadian Association for Curriculum Studies, Lakehead University, Ontario, Canada, v. 13, n. 1, 2015. Disponível em: https://jcacs.journals.yorku.ca/index.php/jcacs/article/view/40246. Acesso em: 8 abr. 2020.

CALABRESE BARTON, Angela; TAN, Edna. A longitudinal study of equity-oriented STEM-rich making among youth from historically marginalized communities. American Education Research Journal, v. 55, n. 4, p. 761-800, 2018. Disponível em: doi:10.3102/0002831218758668. Acesso em 13 abr. 2020. 
CLAPP, Edward P.; ROSS, Jessica; RYAN, Jennifer O.; TISHMAN, Shari. Maker-centered learning: empowering young people to share their worlds. San Francisco: Jossey Bass, 2017.

DE VRIES, Marc J. (Ed.). Handbook of technology education. Springer, 2018. Disponível em: https://www.springer.com/gp/book/9783319446868. Acesso em: 17 abr. 2020.

DEWEY, John. Democracy and education. New York: The Free Press, 1916.

FREINET, Célestin. Educação pelo trabalho. São Paulo: Martins Fontes, 1998.

FREIRE, Paulo. Pedagogia do Oprimido. Rio de Janeiro: Paz e Terra. 1968.

FREIRE, Paulo. Pedagogia da indignação: cartas pedagógicas e outros escritos. São Paulo: Editora Unesp, 2000.

FREIRE, Paulo. Pedagogia da autonomia: saberes necessários à prática educativa. São Paulo: Paz e Terra, 2008.

GERSHENFELD, Neil. How to make almost anything: the digital fabrication revolution. Foreign Affairs, v. 91, n. 6, p. 43-57, 2012.

GILBERT, Jane. Educational makerspaces: disruptive, educative or neither? New Zealand Journal of Teachers' Work, New Zealand, v. 14, n. 2, p. 80-98, 2017.

GIMENO SACRISTÁN, José. O currículo: os conteúdos do ensino ou uma análise da prática? In: GIMENO SACRISTÁN, José; PÉREZ GOMEZ, Ángel I. Compreender e transformar o ensino. 4. ed. Porto Alegre: Artmed, 1998. p. 119-148.

GIMENO SACRISTÁN, José. Poderes instáveis em educação. Porto Alegre: Artes Médicas, 1999.

GIMENO SACRISTÁN, José. O currículo: uma reflexão sobre a prática. 3. ed. Porto Alegre: Artmed, 2000.

HALVERSON, Erica R.; SHERIDAN, Kimberly M. The maker movement in education. Harvard Educational Review, Cambridge, v. 84, n. 4, p. 495-504, 2014.

IANNONE, Leila R.; ALMEIDA, Maria Elisabeth B.; VALENTE, José A. Pesquisa TIC Educação: da inclusão para a cultura digital. In: BARBOSA, Alexandre F. (Coord.). Pesquisa TIC Educação 2015. São Paulo: Comitê Gestor da Internet no Brasil, Centro de Estudos sobre a Tecnologia da Informação e Comunicação, 2016. p. 55-67.

KIM, Youngmoo E.; EDOUARD, Kareem; ALDERFER, Katelyn; SMITH, Brian K. Making culture: a national study of education makerspaces. Technical Report, ExCITE Center, Drexel University, 2019. Disponível em: https://www.researchgate.net/publication/336530623_Making_Culture_A_National_Study_of _Education_Makerspaces. Acesso em: 9 abr. 2020. 
KURTI, R. Steven; KURTI, Debby L.; FLEMING, Laura. The philosophy of educational makerspaces: Part 1 of making an educational makerspace. Teacher Librarian, Bowie, MD, v. 41, n. 5, p. 8-11, 2014. Disponível em:

http://www.teacherlibrarian.com/2014/06/18/educational-makerspaces. Acesso em: 2 abr. 2020.

LECORCHICK, Douglas; SPIRES, Hiller A.; GALLO, Liz. Makerspace curriculum development and implementation. Toward cross-cultural integrative STEM Learning: a United States and China High School Collaboration. Anais..., 2019 American Society for Engineering Education, Southeastern Section Conference. Disponível em: http://www.aseese.org/proceedings/ASEE2019/papers2019/120.pdf. Acesso em: 14 abr. 2020.

MACEDO, Roberto S. Atos de currículos: uma incessante atividade etnometódica e fonte de análise de práticas curriculares. Currículo sem Fronteiras, [s.1.], v. 13, n. 3, p. 427-435, set./dez. 2013. Disponível em:

http://www.curriculosemfronteiras.org/vol13iss3articles/macedo.pdf. Acesso em: 3 abr. 2020.

MARTIN, Lee; DIXON, Colin. Making as a pathway to engineering and design. In: PEPPLER, Kylie; HALVERSON, Erica R.; KAFAI, Yasmin B. (ed.). Makeology: makerspaces as learning environments. New York: Routledge, v. 2, 2016, p. 183-195.

MARTINEZ, Sylvia L.; STAGER, Gary. Invent to learn: making, tinkering, and engineering in the classroom. Santa Barbara: Constructing Modern Knowledge Press, 2013.

MONTESSORI, Maria. Spontaneous activity in education. New York: Schocken Books, 1965.

MOURA, Éliton Meireles de. Formação docente e educação maker: o desafio do desenvolvimento das competências. Orientadora: Belmira Amélia de Barros Oliveira. 2019. Tese (Doutorado em Educação) - Faculdade de Educação, Universidade de São Paulo, São Paulo, 2019. Disponível em: doi:10.11606/T.48.2020.tde-03032020-171456. Acesso em: 14 abr. 2020.

NATIONAL RESEARCH COUNCIL 2014. STEM Integration in K-12 Education: status, prospects, and an agenda for research. Washington, DC: The National Academies Press, 2014. Disponível em: https://doi.org/10.17226/18612. Acesso em: 8 abr. 2020.

PACHECO, José A. Flexibilização das políticas curriculares. Actas do Seminário "O papel dos diversos actores educativos na construção de uma escola democrática". Guimarães: Centro de Formação Francisco de Holanda, p. 71-78, 2000.

PACHECO, José A. Para a noção de transformação curricular. Cadernos de Pesquisa, v. 46 n. 159, p. 64-77, jan./mar. 2016. Disponível em:

http://publicacoes.fcc.org.br/ojs/index.php/cp/issue/view/314. Acesso em: 9 abr. 2020.

PACHECO, José A.; PARASKEVA, João M. As tomadas de decisão na contextualização curricular. Caderno Educação, Pelotas, n. 13, p. 7-18, ago./dez. 1999. 
PAPERT, Seymour. Constructionism: a new opportunity for elementary science education. Proposta para a National Science Foundation, Massachusetts Institute of Technology, Media Laboratory, Epistemology and Learning Group, Cambridge MA, 1986.

PAPERT, Seymour. Situating constructionism. In: HAREL, Idit; PAPERT, Seymour (ed.). Constructionism. Norwood NJ: Ablex, 1991, p. 1-11. Disponível em: http://www.papert.org/articles/SituatingConstructionism.html. Acesso em: 5 abr. 2020.

PEPPLER, Kylie. ReMaking arts education through physical computing. In: PEPPLER, Kylie; HALVERSON, Erica R.; KAFAI, Yasmin B. (ed.). Makeology: makerspaces as learning environments. New York: Routledge, 2016. v. 2. p. 206-225.

RILEY, Erin. What do people learn from using digital fabrication tools? In: BLIKSTEIN, Paulo; MARTINEZ Sylvia L.; PANG, Heather Allen (ed.). Meaningful making: projects and inspirations for fablabs and makerspaces. Torrance CA: Constructing Modern Knowledge Press, 2015, p. 8-13.

ROSE, Mike. The mind at work: valuing the intelligence of the American worker. New York: Penguin, 2014.

SHERIDAN, Kimberly M.; HALVERSON, Erica. R.; LITTS, Breanne; BRAHMS, Lisa; JACOBS-PRIEBE, Lynette; OWENS, Trevor. Learning in the making: a comparative case study of three makerspaces. Harvard Educational Review, v. 84, n. 4, p. 505-531, 2014. Disponível em: doi:10.17763/haer.84.4.brr34733723j648u. Acesso em: 3 abr. 2020.

TRYGGVASON, Gretar; APELIAN, Diran. Re-engineering engineering education for the challenges of the 21st century. JOM-Journal of the Minerals Metals and Materials Society, v. 58, n. 10, p. 14-17, 2006. Disponível em: https://web.wpi.edu/Images/CMS/News/reengineering.pdf. Acesso em: 14 abr. 2020.

VALENTE, José Armando. A espiral da espiral de aprendizagem: o processo de compreensão do papel das tecnologias de informação e comunicação na educação. 2005. Tese (Livre-Docência) - Universidade Estadual de Campinas (Unicamp), Campinas, São Paulo, Brazil. Disponível em:

http://www.bibliotecadigital.unicamp.br/document/?code=000857072\&opt=4. Acesso em: 9 abr. 2020.

VALENTE, José Armando; BLIKSTEIN, Paulo. The construction of knowledge in maker education: a constructivist perspective. Constructivism Foundation, Brussels, Bélgica, v. 14, n. 3, p. 252-262, 2019. Disponível em: https://constructivist.info/14/3/252.valente.pdf. Acesso em: 13 abr. 2020.

VUORIKARI, Riina; FERRARI, Anusca; PUNIE, Yves. Makerspaces for education and training - exploring future implications for Europe. EUR 29819 EN, Publications Office of the European Union, Luxembourg, 2019. Disponível em: doi:10.2760/946996. Acesso em: 08 abr. 2020. 
WEFFORT, Madalena Freire. Observação, registro, reflexão: instrumentos metodológicos I. 2. ed. São Paulo: Espaço Pedagógico, 1996. p. 14.

Recebido em: 20/04/2020

Aprovado em: 11/06/2020 